\title{
Gas Hydrates: the Gent debates. Outlook on research horizons and strategies
}

\author{
J.-P. HENRIET ${ }^{1}$ \& J. MIENERT ${ }^{2}$ \\ ${ }^{1}$ Renard Centre of Marine Geology, Geological Institute, University of Gent, \\ Krijgslaan 281-S8, B-9000 Gent, Belgium \\ ${ }^{2}$ GEOMAR, Research Centre for Marine Geosciences, Wischhofstr. 1-3, D24148 Kiel, \\ Germany
}

In 1811 Sir Humphry Davy, who gained fame for both his research on the methane-laden atmospheres in British coal mines and his synthesis of various new elements and compounds, witnessed the first chlorine hydrate crystallizing. At that time he probably did not imagine that 185 years later methane hydrates would fuel heated debates under the gothic vaults of a former Dominican monastery in Gent.

Natural gas hydrates have come a long way. From a mere chemical curiosity they proved, as early as the mid-1930s, to be a nuisance for the natural gas industry. Its impact increased in the 1970 s, with even the largest pipelines from offshore or arctic fields or the wells from high-pressure underground storage facilities becoming clogged by hydrate plugs. As todays hydrocarbon industry makes a strategic move towards the continental slope, oceanic gas hydrates are increasingly recognized as a major potential hazard for the stability of offshore structures in various deep-water hydrocarbon provinces.

Beyond these direct interferences with man's industrial ventures, gas hydrates are gradually moving onto the foreground of global climate debates. If present estimates of methane hydrate volumes stored in the oceanic margin sediments are substantiated, natural gas hydrates represent, under the present climatic and oceanographic conditions, by far the largest mass of organic carbon stored in a potentially dynamic reservoir of the globe's carbon cycle. Their stability is controlled to a large extent by the temperature regime of the oceans and by pressure conditions on the seabed, both of which are directly linked to sea-level changes.

This vast quantity of 'frozen' greenhouse gas may have played a significant role in the global symphony of ice ages and the dramatic climatic shifts which characterize the Late Cenozoic world. And it may still play a role today, perhaps hardly noticed against the background of the present world's $\mathrm{CO}_{2}$-driven climate machine. But we cannot exclude the possibility that any major modification of the ocean's dynamic ther- mal structure in a warming world might unleash vast amounts of methane from its seabed reservoir. Such a release would potentially contribute to the already anticipated evolution of the Earth's atmosphere, with methane at sometime in the foreseeable future replacing carbon dioxide in its prime role as a global warming agent.

Is such a scenario possible, even plausible? Can we quantify it and introduce it into our models? Does it imply a fundamental change in our modelling approaches, and should the now familiar coupled ocean-atmosphere models give way to coupled seabed-ocean-atmosphere models? Can the estimates of the scale of the hydrate reservoir be substantiated by any ground-truthing? How can the mechanisms of mass and energy transfer between the seabed, ocean and atmosphere, linked to hydrate growth and decay, be unravelled and quantified? And which strategy should be adopted for achieving such ambitious goals?

This profusion of questions, in the first instance, calls for dialogue and concerted efforts between various disciplines, from geophysics and geochemistry to ocean and atmospheric physics and chemistry, sedimentology, thermodynamics, ice core stratigraphy, biogeochemistry and many more fields of research. The questions prompt immediate dialogue between academic and industrial partners and call for sustained, longterm efforts, focused in their objectives but global in their relevance.

Such questions were also the subject of the workshop 'Gas hydrates: relevance to world margin stability and climatic change', organized in Gent in September 1996 under the auspices of the European Commission's Marine Science and Technology (MAST) Programme and the European Marine and Polar Science Boards (EMaPS).

This eminent patronage occurred because of the outstanding fundamental scientific relevance of this topic, which truly blends with far-reaching economical and societal considerations, and because the northwest European continental 
margin, Europe's new frontier for hydrocarbon resources, turns out to be a vast natural laboratory for the interaction between gas hydrates and slope stabilities, where some of the world's largest submarine slides have yet to be studied with advanced research. This is exactly the type of natural European laboratory which has the potential to lead to fundamental breakthroughs of global relevance.

With such outstanding natural laboratories along Europe's margins, research will transgress the European scientific and human dimensions. The interaction between oceanic conditions and the seabed along the North Atlantic margins is a basin-wide scientific challenge that calls for organization and, wherever possible, cooperation with U.S. and Canadian partners. On Europe's northern frontier, in the Arctic seas, and on its southern flank, in the eastern Mediterranean and Black Sea, hydrate research has been pioneered by Russian institutes, which are becoming Europe's active partners. Last but not least, Europe should not overlook the important momentum in fundamental and applied hydrate research in the Far East, particularly at Japanese institutes.

This volume draws on state-of-the-art hydrate research information from leading scientists, from the USA, Russia and the European Union. Kvenvolden (US Geological Survey in Menlo Park) and Sloan (Colorado School of Mines) set the stage for the volume. Both take the reader on a journey from the fundamentals of oceanic hydrates, or clathrates, to their vision of the relevance of hydrates as an energy resource, as a factor of margin stability and of climatic change. This journey benefits from both the affinities and the differences in perspective of both authors, partly due to the different 'cultural' environments from which they come. Kvenvolden builds upon USGS databases to highlight the geological occurrence and the resource dimension of gas hydrates in a global context, while Sloan utilizes his laboratory studies to introduce the reader to the fundamental physical and chemical properties of gas hydrates, their characterization and kinetics of formation and decay. The latter contribution sets the stage for the following chapter, which addresses some fundamental insights into hydrate generation and identifies challenges in modelling.

The following sections of this introductory paper summarize the outcomes of the round table debates which animated the Gent workshop, and introduce papers in this volume. It should be emphasized that where present-day forums on oceanic gas hydrates research cur- rently encompass the trilogy 'resource-hazardclimate issue', as introduced by Kvenvolden and Sloan, the Gent workshop deliberately focused on slope stability and climatic issues. The contents and structure of this Special Publication reflect this focus.

The first round table discussion of the workshop focused on the challenges ahead in understanding the generation of oceanic gas hydrates and in assessing the physics and chemistry of oceanic hydrate-bearing sediments. Contributors to the discussion were Ben Clennell and Gabriel Ginsburg (panel members), Myriam Kastner (moderator), Hans Amann, Bill Dillon, Bilal Haq, Jean-Pierre Henriet, James Kennett, Keith Kvenvolden, Dave Long, Charles Paull, Carolyn Ruppel, Alister Skinner, Dendy Sloan, Tjeerd Van Weering and Warren Wood.

\section{Analysis and modelling of hydrate formation}

A prime question emerging from the debate is how we actually view the hydrate zone as a complex, multiphase system and in particular how we view multiphase fluid transport and hydrate generation in porous media. There are still vast opportunities offered to hydrate research to draw upon the extensive literature in related fields such as chemical engineering (chemical reactors) and various fields of civil engineering, and to design suitably controlled experiments. An important issue is the residence time of gas within the hydrate stability zone. Only a minor portion of the gas migrating through a hydrate stability zone seems to be actually trapped in hydrates. The kinetics of such entrapment needs clarification. However, it is clear that the host sediments are not merely behaving as a passive matrix in which hydrates accumulate. Surface forces on mineral particles may control the kinetics of hydrate formation and the stability of hydrates in the sediment pores. And it is the grain size which is likely to control the spatial distribution of hydrates: in coarse sediments, gas hydrates are often found to cement the grains throughout the matrix, whereas in finer sediments they frequently occur as discrete nodules, sheets or lenses.

Ginsburg focuses on the spatial variability of gas solubility in pore waters, and highlights the inhomogeneous distribution of hydrates within the hydrate stability zone. Rempel \& Buffett venture to construct relatively simple models that quantitatively predict the development of hydrate layers, both for advection of gas from deeper reservoirs and for in situ biogenic production. The latter model meets Ginsburg's observa- 
tion about a shallow region with elevated hydrate saturation. Natural gas hydrates however do not have a simple composition: they are solid solutions of water and a variety of gases such as $\mathrm{CO}_{2}, \mathrm{CH}_{4}, \mathrm{~N}_{2}$ and $\mathrm{C}_{2} \mathrm{H}_{6}$, and may contain significant concentrations of $\mathrm{H}_{2} \mathrm{~S}$. Bakker develops and models stability conditions for fluid systems and gas clathrates with a complex composition, thoroughly testing them against experimental data. Lu \& Matsumoto focus on the formation of $\mathrm{CO}_{2}$ hydrates under varying $\mathrm{pH}$ conditions.

\section{Exploration strategy and field evaluation methodology}

The habitat of hydrates in sediments will control their geophysical response, whether electrical, seismic or thermal. The calibration of geophysical responses will require extensive ground-truthing through drilling and the recovery of undisturbed samples for analysis in the laboratory under the original ambient pressure. This calls for the development of a new generation of pressure core samplers and core logging devices, as well as instruments allowing imaging (NMR imaging, CAT-scanning) and controlled experiments inside pressurized cores. Only this type of approach will allow the proper calibration of downhole logging responses.

Booth et al. introduce a comprehensive first overview of the spatial distribution of hydrates in various 'reservoirs' and environments, as appraised from numerous well sites located around the world. Goldberg \& Saito comment on the results of downhole logging on the ODP Blake Ridge sites, standing up for 'loggingwhile-drilling' in hydrate investigations.

In general, geophysics has the potential to achieve more than it has to date. While significant research is still needed to understand the true physical nature of the BSR (the 'bottom simulating reffector'), it is necessary to treat it on its own merits and, through the above calibrations and a move towards more high-resolution seismics, further focus on the most significant sedimentary section, which stretches from the BSR to the seabed.

Both Hobro et al. and Tinivella et al. demonstrate the power of seismic tomographic inversion studies for elucidating the velocity distribution above BSR horizons. Mienert et al. discuss high-resolution results obtained from ocean bottom seismometers and from modelling using trial and error ray tracing.

But how far can we go with ground-truthing? The exploration phase for oceanic hydrates is in its early stages. We are still seeking to identify the physical criteria which will allow mapping of hydrate reservoirs: 'BSR'-mapping is still the only, and debatable, strategy. There is an urgent need for ample drilling efforts and adequate sample recovery. In most cases targets will call for three-dimensional approaches. However, drilling is expensive, so a strategy is needed and site selection criteria have to be identified. Ground-truthing should focus on end members and type localities which span a wide spectrum of hydrate habitats. Research should proceed until each end member, in each type of hydrate accumulation, is categorized.

There was a consensus in the workshop debates that sites for investigation should ideally be selected where seeps are observed, and that such seeps need to be quantified, and qualified. This calls for monitoring of fluxes and for sample collection and in situ chemical analyses. It is important to assess how much gas is seeping from hydrate zones and non-hydrate zones, from focused vents and diffuse venting areas. How much is released as a steady state flow, and how much as episodic venting, inasmuch as the latter can be evaluated during times available for observation.

We need fresh observations of modern venting systems in order to try to understand their dynamics. We can only issue warnings today about trends in $\mathrm{CO}_{2}$ levels in the atmosphere because of decades of observation. The basic technology is available, and improvements of instruments are straightforward. Even low-cost, long-term thermistor stations can teach us how temperature drives the system. If we are truly convinced that the issue is scientifically important, we must start monitoring stations in the deep sea. Over a time scale of a few decades, especially in areas prone to slope instabilities, an event will eventually happen that we will be able to record.

\section{Major gas hydrate occurrences: case studies}

A second debate at the workship ventured to target areas where international and multi-disciplinary research efforts, over a sustained period, may shed light on significant oceanic gas hydrate occurrences and quantify the elements needed for both resource assessment and climatic modelling. Contributors to the debate were Bill Dillon and Michael Ivanov (panel members), Jürgen Mienert (moderator), Mike Baillie, Angelo Camerlenghi, Gabriel Ginsburg, Myriam Kastner, Bilal Haq, Mike Helgerud, Jean-Pierre Henriet, Charles Paull, Dominique Raynaud, Carolyn Ruppel, Dendy Sloan and Warren Wood. 
Introducing the evaluation of potential target areas raised the issue of gaps in our approaches: both topical gaps and scale gaps. We have already come a long way in bridging topical gaps, in particular between geophysical research and geochemical investigations, which have dominated the scene so far, by the study of chemical gradients over large sections, laboratory studies, well logging and thermal studies. But we still have scale gaps. Somewhere between the scale of molecules and logging scales we already seem to have a problem. What is going on within the pores? What is going on at a scale of centimetres to metres? This is where much more research involvement is required.

Such involvement will primarily require field exploration and experiments, initially using downhole experiments. We need to look at hydrates even before they are brought up the hole. For such purposes some field study sites should be set up and agreed upon by a wide research community. Places where high concentrations of gas hydrates are found and where the geological background is already well documented should be used for such experiments.

Still on the question of scales, but at the other end of the spectrum: as we move towards analysing the possible coupling between ocean and seabed through bottom currents, the transmission of thermal pulses from a warming or cooling atmosphere via the hydrosphere to the seabed and the resulting decay or growth of oceanic hydrates, the responses of slopes through giant slides or sequences of slides, we analyse basinwide phenomena. The logical scale for studying the climatic role of hydrates and for making the link with thermal models of the ocean will be the oceanic basin, such as the North Atlantic, or the Arctic. In a climate perspective, the choice of study sites should also aim to clarify the behaviour at the basin scale.

In the Atlantic, following ODP Leg 164, the Blake Ridge is probably one of the best known hydrate areas. Paull et al. and Thiéry et al. report on the preliminary field data and some most interesting geochemical analyses of pore fluids. New ideas will be developed from the research that has been done so far and this is a sound reason for re-visiting these sites to check these ideas, to validate the models on the holes and to continue research, with high-resolution geophysics on the well sites and with a possible move towards in situ experimenting and monitoring. But for research within the context of European programmes, more proximal target areas will have to be identified.

Europe's Mediterranean flank and, in particular, the eastern Mediterranean and the Black Sea, offer attractive perspectives though specifically in relation to the geodynamic setting of convergent margins and to the particular oceanographic environment of confined seas. The association of seeps with mud volcanism and $\mathrm{H}_{2} \mathrm{~S}$ degassing is important, while there is an ample background database including multibeam, single- and multichannel seismic data. The Black Sea offers the possibility of a transect from the deep-sea to the shelf and even to the land, and the chance to observe a whole range of degassing processes and the distribution of hydrates as a function of water depth. Shallow and relatively nearshore sites would allow cost-effective re-sampling and monitoring.

De Lange \& Brumsack report on gas hydrates from mud domes in the eastern Mediterranean and present what is probably the first estimate of the total amount of shallow methane associated with mud dome structures on the eastern Mediterranean Ridge. Their results, seen against a background of the recently discovered fast rise in bottom-water temperature in the Mediterranean, have a particular significance. Woodside et $\boldsymbol{a l}$. describe gas hydrates and mud volcanoes associated with the Anaximander Mountains offshore southwest Turkey, in the vicinity of recently discovered giant mass movements such as the Great Slide in the eastern Mediterranean. Deep fluid fluxes and hydrate accumulations associated with authigenic carbonates and bacterial mats are reported by Ivanov et al. and Bouriak \& Akhmetjanov on the Crimean continental margin in the Black Sea.

The degassing potential of the eastern Mediterranean and the Black Sea brought human development into focus at the Gent workshop. The eastern Mediterranean, being the cradle of our literate civilisation, has generated a 5000 year long human record, which, on at least one occasion, underwent total collapse. Without directly suggesting a causal link, we should bear in mind that gas release, especially when toxic gases like $\mathrm{H}_{2} \mathrm{~S}$ are implied, may constitute a significant hazard.

If, however, we are looking for recent significant hydrate destabilization and seabed degassing related to temperature rise, we should probably focus on Europe's northernmost facade, the Arctic Seas. Deglaciation caused the sudden flooding of vast areas of Arctic shelves by water that was $30^{\circ} \mathrm{C}$ warmer than the formerly exposed substratum. If there is any place in the world where hydrate breakdown should have manifested itself, it should be in the high-latitude shelf seas.

Though Long et al. do not directly address the former issue, which was raised in the debate at 
the workshop, their observations in the Barents Sea still suggest that the present-day decay of hydrates near large sea-floor craters supplies widespread methane plumes which fluctuate in response to seasonal warming of the bottom water. Later in this book Mienert et al. interpret similar observations differently.

Authors like Veerayya et al., Neben et al. and Delisle et al. remind us of the significant hydrate potential of Indian and southeast Asian continental margins. The last paper models the recovery of a BSR after a thermal disturbance at the sea floor due to slumping, for instance. Such modelling seems to show that the repositioning of a BSR is a very slow process, taking place over thousands of years.

There was a consensus in the conclusions of the workshop debate that focusing on a few areas with a multidisciplinary approach is an essential objective. The selection of such areas however requires more preparation.

\section{Relevance to margin stability and climatic change: research horizons}

Delisle et al.'s exercise in the recovery of a thermal equilibrium in hydrate stability zones following a major disturbance of the seabed indirectly links with what certainly turned out to be the most stimulating and 'debatable' issue of the Gent workshop, i.e. the possible coupling of oceanic gas hydrates, margin instabilities and climate. This brought scientists from different backgrounds into direct discussion. The direct confrontation of ideas between atmospheric modellers and ice core scientists on one side and hydrate geochemists and geophysicists on the other side turned into a captivating experience, which left both parties with a taste for more.

Participants in this debate were Charles Paull, Dominique Raynaud and Robert Thorpe (panel members), Dendy Sloan (moderator), Hans Amann, Lars Berge, Angelo Camerlenghi, Bill Dillon, Bilal Haq, Myriam Kastner, Peter Kennett, Tom McGee, Walther Van Kesteren and Warren Wood.

It is widely recognized that the present-day, steady-state methane release from the ocean, including from oceanic hydrates, is not impressive and that much larger releases, which could affect climate, call for dramatic events such as giant slides which, by one mechanism or another may find their origin in the decay of hydrate horizons on the continental slope. It is already known, through extensive acoustic mapping, that vast stretches of the oceanic margins, in par- ticular the North Atlantic, show evidence of major large-scale slides and slumps.

The basic mechanisms through which decaying hydrates may affect the stability of slopes are still poorly understood. Overpressure in the pores below a decaying hydrate base may account for a decrease in shear strength, but no experimental evidence for any overpressure under BSR horizons has been put forward to date. Any build-up of overpressure will depend upon the balance between hydrate decay and pressure dissipation through possible permeability barriers. Furthermore, and by analogy with the rationale behind the analysis of the generation of hydrates, we should not regard a slope sediment as a simple, passive matrix, in particular not along formerly glaciated margins. The nature of the clays significantly controls the stability of the sediments, and for some clays in particular the stability of the particle matrix is directly controlled by the sodium content of the pore water. Any freshening of the pore water, e.g. by hydrate decay, may decrease the sodium concentration and hence trigger slope instabilities through a possible 'quick clay' behaviour. The most dramatic examples of quick clay surges which have been documented occur in glacial sediments of the Scandinavian and Canadian coastal plains and valleys which were deposited in submarine environments and subsequently uplifted and then leached by freshwater infiltration.

Mienert $\boldsymbol{e t}$ al. demonstrate that deep-water gas hydrate horizons are coincident with areas and depths of slope failures in continental margin sediments along the north-eastern Atlantic margin, in particular in the Storegga slide area. While across the Atlantic, in the Blake Ridge hydrate province, faulted and collapsed depressions clearly seem to root at the base of the hydrate stability zone and are interpreted by Dillon et al. in terms of overpressure of gassy sediments just below the zone of hydrate stability.

Another process which needs clarification is the fate of steady fluxes of methane from hydrate reservoirs to the seabed and from the seabed to the sea surface and atmosphere. We need to understand the process of transport of gas across geochemically active horizons like the sulphate reduction zone. And beyond the seabed, what is the fate of methane in the water column, as a function of discharge rate, bubble size and dynamics? Do we fully master the chemical kinetics, and have we a feeling of how much is subject to oxidation and take-up by the biosphere on the way to the surface? The absence of experts in this field was seen to represent a knowledge gap at the workshop. 
If any significant slide-induced flux of methane from the ocean to the atmosphere is substantiated, the next step is to attempt to calculate and model the radiative forcing of potentially large and sudden releases of methane on climate change.

It is clear that we need to understand the relative sensitivity of the whole environment in which clathrates occur and decay, in which methane migrates, and the relative sensitivity through time. We have evidence of rapid major climate changes in the Quaternary and there is no answer so far as to what is forcing these rapid changes. We have evidence of major slide events in the Quaternary, and suspect a significant coupling, but have no real clues yet. But as the past is the key to the future, we have to scrutinize long-term records of slope instabilities and fast climate changes to gather such data.

Haq reviews the possible coupling mechanisms between seabed degassing and climatic changes and screens possible long-term climatic and slope-stability records. Stable isotope records suggest the Late Paleocene - Early Eocene warming peak may be a past analogy, which could offer further clues about the behaviour of gas hydrates and their contribution to global warming. He also digs into the more remote past, towards 'pre-psychrospheric' times.

A study of the stable isotope record of the Santa Barbara Basin off California (an oral communication by Peter Kennett et al. at the Gent workshop) based on recently drilled ODP holes has revealed rapid warming events which can be explained by seabed degassing, and that seem to be synchronous with warmings associated with Dansgaard-Oeschger events recorded in Greenland ice cores. One reason why clathrates have so far not emerged as a dynamic component of the climate machine is that for a long time there has been a sense that the deep seas beyond the continental shelves were relatively stable in terms of hydrographic conditions. One of the results coming out of ODP and in particular from the Santa Barbara data is that this is not true. At least in the Northwest Pacific, physical oceanographic conditions have been very unstable in Quaternary times, with bottomwater temperatures varying up to $3^{\circ} \mathrm{C}$, which is very significant in terms of hydrate stability. Hydrates can thus be produced and released in a pumping type mechanism, that could affect global climate change. However the global relevance of results from one basin must be treated with caution until they can be substantiated by further data.

As emphasized by the climatologists and icecore scientists at the workshop, what turns out to be a priority now, certainly if we are aiming to model a possible coupling between seabed and atmosphere, is the need to refine the sampling resolution and hence the time resolution in all these records and thus allow reliable correlations and identification of lead and lag mechanisms.

Thorpe et al. model a 'Catastrophic Hydrate Release' (CHR) of methane at the termination of the last glaciation as indicated by ice core results to test its potential impact on glacial climate. They come to the conclusion that methane alone could not trigger deglaciation. However. a combination of methane release, increase in carbon dioxide and changes in heat transport by the ocean - coupled with high climate sensitivity - could simulate changes of the observed magnitude. Raynaud et al. also confirm that present evidence from ice cores does not show evidence for CHR, but the resolution of the ice record is not refined enough to unequivocally resolve leads and lags between methane and carbon dioxide surges and temperature rises. According to Thorpe et al., if the GRIP core sampling interval could be reduced to allow a resolution of around 50 years, then it would be possible to more fully test the CHR hypothesis.

Still a major issue for the climatic relevance of the world hydrate reservoir is the validation of its size, at a global scale. We will never achieve accurate estimates, but we need meaningful estimates. Can the Blake Ridge results be regarded as representative of other rich hydrate provinces, or is it an exception? This question leads us back to the exploration and ground-truthing debate, which is most significant for the estimation of the relevance of oceanic hydrates for the Earth's climate.

Beyond these scientific arguments, the climate debate has profound human dimensions of culture, communication and strategic priorities. As suggested by a climate modeller at the workshop. we might wonder why the climate modelling community has traditionally paid so little attention to the significance of gas hydrates, though there is increasing evidence of their huge potential. One reason is that the climate community is presently deeply concerned with trying to understand what is going on now and what is going to happen in the near future, and what we might be about to do to the climate system other than what we are doing at this time.

It is a matter of economic pressure, of population growth, of how much energy resources are going to be used, of how much $\mathrm{CO}_{2}$ will be emitted. In this process, uncertainties are large

about emissions, about climate sensitivity. about the climate response to forcing by greenhouse gases - and it is generally felt that these 
uncertainties coupled together are very much greater than the potential uncertainties associated with the possible release of clathrate gases in the future. That is, to a large extent, why clathrate research has traditionally had a low profile.

\section{Which strategy for international cooperation?}

The final Gent debate focused on defining strategies for international and multidisciplinary research efforts. Participants were Jean Boissonnas (EC MAST), Bilal Haq and R. Heinrichs (NSF), Laurent d'Ozouville (EMaPS) (panel members), Jean-Pierre Henriet (moderator), Ray Cranston, Jean-Paul Foucher, Myriam Kastner, Jim Kennett, Tom McGee, Dominique Raynaud, John Roberts, Carolyn Ruppel and M. Veerayya.

The challenge of unveiling the possible coupling of the seabed and climate through gas hydrates is a topic of global cooperation across discipline boundaries. Over the next decade, the Ocean Drilling Program will include a significant component looking at gas hydrates, with one or more focused legs, but it is resource-limited. Other organizations are needed, other science structures that will enable the scientific community to get at the fully multidisciplinary and interdisciplinary nature of clathrates. The possible input of a Japanese drilling ship, currently at the planning stage, might broaden the scientific perspectives for hydrate research.

For the European Union, the Gent workshop coincided with the drafting of the 5th Framework Programme (5th FP) which will significantly differ in its structure and objectives from the previous programmes. Emphasis will be laid on industry-driven research, research that more closely answers the needs of society, and research on the environment and the resources of the living world. Clathrate research could fit into such schemes, provided scientists can convey the proper messages to their national authorities as the 5th FP is finalized.

But whatever the prospects may be, European Union support would necessarily focus on European margins. These include the Mediterranean Sea, and possibly the Black Sea. However, such priorities do not preclude international agreements, and talks have been opened with the US Administration to draft an official agreement which includes matters relating to marine science and technology. At present teams from the US, Canada and Australia can join EU teams on a project provided they bring their own funding. Cooperation schemes with Russian partners also exist and will be developed. Regarding cooperation with a country with advanced clathrate research like Japan, farstretching bilateral agreements are already in place with the US and Canada respectively which focus on Pacific basins research and matters of technology. However cooperation with other partners, in particular along the Indian Ocean margins and in southwest Asian regions, should not be overlooked.

Still on the European scene, the European Board for Marine and Polar Science (EMaPS) has promoted communication (networking) among scientists and the case for a European strategy for ocean drilling, involving a new synergy with industrial partners. Two workshops have already been organized, one on scientific strategies in Europe for ocean drilling, including ODP and programmes like CORSAIRES or IMAGES, and another to identify new technologies for scientific drilling.

In terms of programmes, attention should also be paid to the US MARGIN initiative, on its way to becoming internationalized. The British and French continental margins communities have recently started their own programme. Such programmes include fluid flow as a broad general topic and encompass clathrate research.

Throughout these programmes, technology development for exploration, for ground-truthing and for monitoring needs to be a focal point. Communication of data is also important, as is sharing of equipment to collect new data. It is the conveners' hope that the Gent workshop and its debates will contribute to these objectives.

The Gent workshop 'Gas Hydrates: Relevance to World Margin Stability and Climatic Change' was supported by the EC MAST 3 Concerted Action CORSAIRES. Behind the convenors' names, a large team contributed to the success of the workshop and the editing of this volume. Special credit goes to Tine Missiaen, Maarten Vanneste, Marc De Batist, Marc Faure Didelle and Dries Declercq. Alister Skinner and Dan Evans from the British Geological Survey are gratefully acknowledged for a careful reading of this manuscript.

\section{Professor Robert Kidd}

Professor Robert Kidd was keen to be among the participants of the workshop 'Gas Hydrates: Relevance to World Margin Stability and Climatic Change'. Relevant work he intended to propose dealt with sediment instability on the margin of the Canaries, as part of the EC MAST2 'STEAM' project, and with methane driven mud volcano extrusion on the Mediterranean Ridge, as part of TREDMAR. He also 
planned a more general talk on JOIDES' interest in gas hydrates, based on ODP's Long Range Plan: a topic he already had brilliantly presented in front of the EMaPS Marine Board in Rotter- dam, on 9 May 1996. Tragically, Rob passed away a few weeks later, in early June, aged 48. His manifold contributions to marine sciences will be sadly missed.

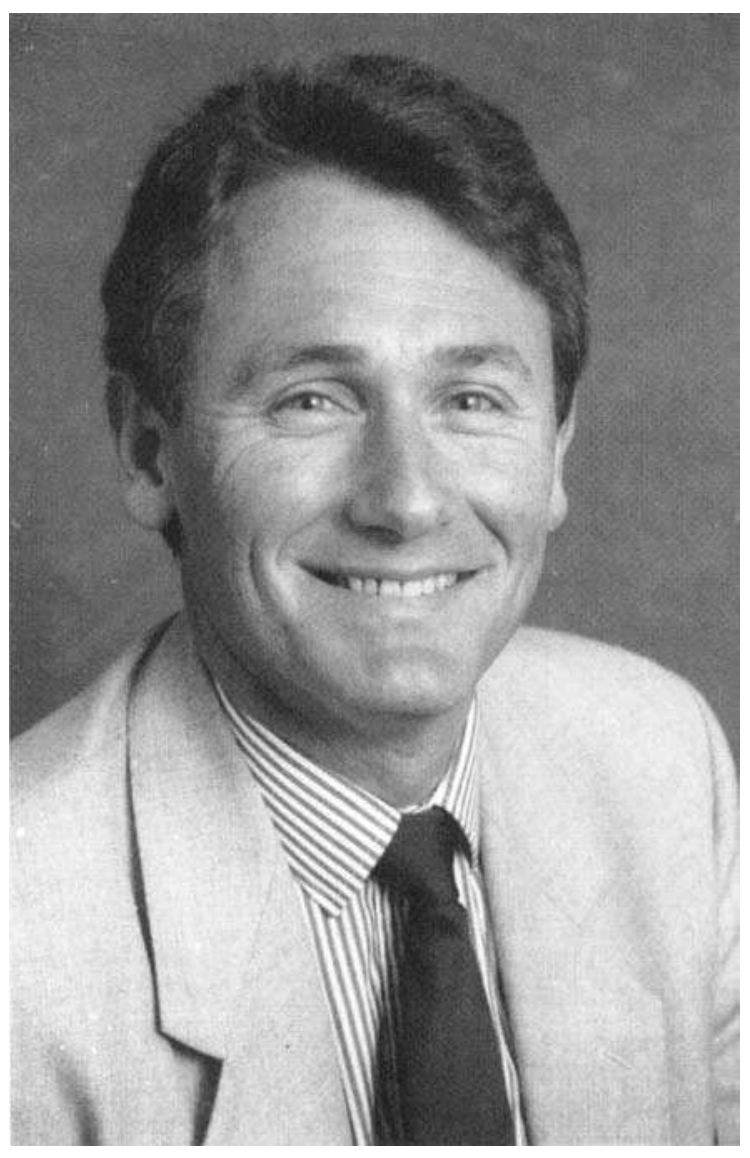

